International Journal of Medical Anesthesiology 2020; 3(1): 224-227

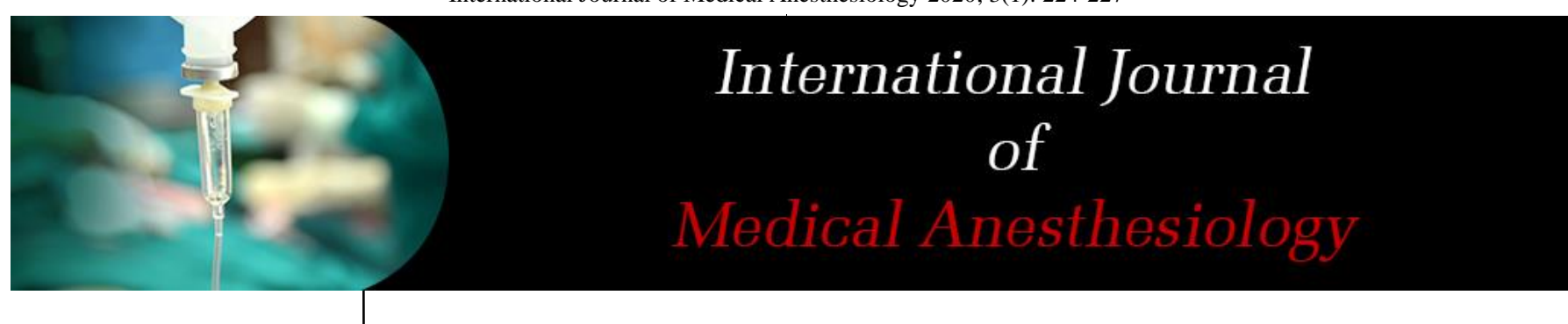

E-ISSN: 2664-3774

P-ISSN: 2664-3766

www.anesthesiologypaper.com

IJMA 2020; 3(1): 224-227

Received: 03-11-2019

Accepted: 07-12-2019

Dr. Tulsi T

Assistant Professor,

Department of

Anaesthesiology, Bangalore

Medical College and Research

Institute, Bengaluru,

Karnataka, India

Dr. Bharathi BM

Assistant Professor,

Department of

Anaesthesiology, Bangalore

Medical College and Research

Institute, Bengaluru,

Karnataka, India
Corresponding Author: Dr. Bharathi BM

Assistant Professor,

Department of

Anaesthesiology, Bangalore

Medical College and Research

Institute, Bengaluru,

Karnataka, India

\section{Anaesthetic management of obstetric and nonobstetric emergencies during pregnancy}

\author{
Dr. Tulsi T and Dr. Bharathi BM
}

DOI: https://doi.org/10.33545/26643766.2020.v3.i1d.92

\begin{abstract}
Background: Obstetric anaesthesia is considered to be one of the higher risk areas of anesthetic practice. The present study is done to know the various anesthetic techniques in management of obstetric emergencies and their complications.

Materials \& Methods: This was a descriptive study of 100 pregnant patients coming for emergency surgeries. Intraoperative complications such as hypotension, bradycardia, failed spinal, high spinal, seizures, difficult intubation and aspiration were recorded.

Results: $78 \%$ of the obstetric emergencies were lower segment caesarean section, $16 \%$ was surgery for ectopic pregnancy, $3 \%$ hysterectomy for postpartum hemorrhage, $1 \%$ bartholin cyst excision, $1 \%$ I and $\mathrm{D}$ and $1 \%$ cervical encirclage. $90 \%$ of caesarean sections received subarachnoid block. $8 \%$ of cases received general anaesthesia and $2 \%$ of case subarachnoid block was converted to general anesthesia. 17 cases previous caesarean section in labour, in 13 cases thick meconium stained liquor with foetal distress, in 6 cases failure to progress, in 5 cases cephalopelvic disproportion, in 5 cases premature rupture of membranes and in 4 cases breech presentation in labour. Hypotension was present in 20 cases, bradycardia in 2 cases and failed spinal in 2 cases.

Conclusion: Authors concluded that single shot subarachnoid block is the most common method of anaesthesia for emergency caesarean sections.

Chickenpox is a worldwide disease and is no respecter race or class. The incidence increases in spring $\&$ winter months in the temperate zones. In the tropics, the peak incidence is during winter and early spring. The disease in fact started is helping the virus to spread rapidly.
\end{abstract}

Keywords: Caesarean, pregnancy, subarachnoid block

\section{Introduction}

Obstetric anaesthesia is considered to be one of the higher risk areas of anesthetic practice. Maternal adaptations to pregnancy and the care of both the mother and the fetus present unique challenge to the obstetric anesthesiologist. ${ }^{1}$ Obstetric anesthesia practice has had an important influence on maternal mortality, as failed airway management is the predominant cause of anesthetic related airway mortality. Estimates of the frequency of nonobstetric surgery performed during pregnancy range from $0.75 \%$ to $2 \%$. Emergency surgery is indicated during pregnancy for the management of trauma, malignancy or acute medical illness. More recently procedures have been developed for the treatment of fetal abnormalities which produce progressive injury in-utero before the fetus has reached a viable gestational age ${ }^{[2,3]}$

Maternal adaptations to pregnancy pose hazards for the mother and fetus during surgery. Additional risks for the fetus include the following:

1. The effects of the disease process itself or of related therapy.

2. The possible teratogenicity of anesthetic agents.

3. Intraoperative perturbations of uteroplacental perfusion and fetal oxygenation.

4. The risk of abortion or preterm delivery ${ }^{[4,5,6]}$.

There has been increasing trend in the caesarean section in the last two decades.. An increase in emergency caesarean sections has been attributed to more advanced intrapartum foetal monitoring, allowing obstetricians to diagnose intrapartum foetal compromise earlier and more effectively.

The incidence of anesthesia-related maternal mortality has declined. Anesthesia remains responsible for approximately $3 \%$ to $12 \%$ of all maternal deaths. The majority of these deaths 
occurs during general anesthesia and result from failed intubation, failed ventilation and oxygenation, and pulmonary aspiration of gastric contents. Associated factors include obesity, hypertensive disorders of pregnancy, and emergently performed procedures ${ }^{[6-8]}$.

This present study is done to know the various anesthetic techniques in management of obstetric emergencies and their complications.

\section{Materials and Methods}

This was a descriptive study of 100 pregnant patients coming for emergency surgeries in JSS Hospital, Mysore. All patients were informed regarding the study and written consent was obtained. Data was collected according to predesigned proforma. The technique of anesthesia and the drugs to be used was decided by the attending anesthesiologist.

For subarachnoid block, after Preanesthetic evaluation, a18G peripheral venous access was established in the upper limb and preloaded with $0.9 \%$ Normal saline. Oxygenated through ventimask at $5 \mathrm{~L} / \mathrm{min}$. Basal Pulse rate, ECG, $\mathrm{SpO}_{2}$ and BP was recorded. Patient was placed in left lateral decubitus position to prevent supine hypotension. Under aseptic precautions, after infiltration of skin and subcutaneous tissues with $2 \mathrm{ml}$ of $2 \%$ lignocaine, 25G Quincke spinal needle was advanced between L3-L4 vertebral spinous process and after confirming free flow of clear CSF, $2 \mathrm{ml}$ of $0.5 \%$ hyperbaric bupivacaine was introduced. Patient was turned supine. Patient was positioned with $10^{\circ}-15^{\circ}$ left tilt. Fall in MAP> $10 \%$ of baseline value was treated with IV fluids, oxygen, bolus of $6 \mathrm{mg}$ I.V mephentermine and, fall in $\mathrm{HR}<50 \mathrm{bpm}$ was managed with $0.6 \mathrm{mg}$ atropine.

In case of caesarean section on delivery of the baby, 10 units of oxytocin were given in $500 \mathrm{ml}$ NS as infusion. Any blood loss was replaced with crystalloids initially, then with colloids and if needed with blood. At the end of surgery, the level of block was assessed and $\mathrm{BP}, \mathrm{SpO} 2, \mathrm{ECG}$ and $\mathrm{HR}$ were monitored in the Post anesthetic care unit, till the level of sensory block descended to T10.

For general anaesthesia, after preanaesthetic evaluation and informed consent, an $18 \mathrm{G}$ peripheral venous access was established in the upper limb. Basal ECG, $\mathrm{SpO}_{2}, \mathrm{HR}$ was recorded. Patient was positioned with $10^{\circ}-15^{\circ}$ tilt. Patient was premedicated with inj. metoclopramide $10 \mathrm{mg}$, inj ranitidine $50 \mathrm{mg}$ and inj glycopyrrolate $0.2 \mathrm{mg}$ IV. Patient was pre-oxygenated with $100 \% \mathrm{O}_{2}$ for 3 min, after which a rapid sequence induction was done with the intravenous induction agent and patient was paralyzed with $2 \mathrm{mgkg}^{-1}$ of succinylcholine. After fasciculation pass the abdomen direct laryngoscopy was done and intubated with $7 \mathrm{~mm}$ cuffed PVC endotracheal tube, bilateral air entry confirmed and secured. Patient was maintained on $\mathrm{O} 2$ (FiO2-0.5), with nitrous oxide. In case of caesarean section on delivery of baby 10 units oxytocin was given in $500 \mathrm{ml} \mathrm{NS}$ as infusion and inj fentanyl $1 \mu \mathrm{gkg}^{-1}$ was given IV. FiO2 was reduced to 0.35 . Any blood loss was replaced with crystalloids initially, then with colloids and if needed with blood. Adequate neuromuscular blockade was maintained with repeated doses of atracurium $0.1 \mathrm{mgkg}$-1 or vecuronium $0.02 \mathrm{mgkg}^{-1}$. At the end of surgery, after patient initiated spontaneous respiration, neuromuscular blockade was reversed with neostigmine $0.05 \mathrm{mgkg}^{-1}$ and glycopyrrolate $10 \mu \mathrm{gkg}^{-1}$. Patient was extubated after she is fully conscious and regained adequate muscle power. She was shifted to PACU and $\mathrm{HR}, \mathrm{ECG}, \mathrm{BP}, \mathrm{SpO}_{2}$ was monitored and $\mathrm{O}_{2}$ provided through face mask at $5 \mathrm{~L} /$ minute for five hours.

Maternal hemodynamics (HR, SBP, DBP, Mean BP, $\mathrm{SpO}_{2}$ )the baseline values were measured just before the subarachnoid block is given or the patient in induced, and were recorded at every 2 minute interval, till 10 minute, every 5 minutes from 10 minute before extubation till 5 minute after, if the patient is under GA.

Intraoperative complications such as hypotension, bradycardia, failed spinal, high spinal, seizures, difficult intubation and aspiration were recorded. Data was collected and statistical analysis was performed as explained in the methodology of the study.

\section{Results}

Table 1: Type of surgery

\begin{tabular}{|c|c|}
\hline Surgery performed & No of patients (\%) \\
\hline CS & 78 \\
\hline Lap assisted salpingectomy & 4 \\
\hline Laparotomy and salpingectomy & 12 \\
\hline Cyst excision & 1 \\
\hline I and D & 1 \\
\hline Cervical encirclage & 1 \\
\hline Hysterectomy & 3 \\
\hline
\end{tabular}

Table 1 shows that $78 \%$ of the obstetric emergencies were lower segment caesarean section, $16 \%$ was surgery for ectopic pregnancy, 3\% hysterectomy for postpartum hemorrhage, $1 \%$ bartholin cyst excision, $1 \% \mathrm{I}$ and D and $1 \%$ cervical encirclage.

Table 2: Technique used for CS

\begin{tabular}{|c|c|}
\hline Technique used for CS & No of patients (\%) \\
\hline SAB & 90 \\
\hline GA & 8 \\
\hline SAB/GA & 2 \\
\hline
\end{tabular}

Table 2 shows that in $90 \%$ of caesarean sections received subarachnoid block. $8 \%$ of cases received general anaesthesia and $2 \%$ of case subarachnoid block was converted to general anesthesia.

Table 3: Level attained in subarachnoid block

\begin{tabular}{|c|c|}
\hline Level attained & No of patients \\
\hline $\mathrm{T} 4$ & 46 \\
\hline $\mathrm{T} 6$ & 33 \\
\hline $\mathrm{T} 10$ & 1 \\
\hline
\end{tabular}

Table 3 shows that T4 was achieved in 46 cases, T6 in 34 cases and in case $\mathrm{T} 10$. 


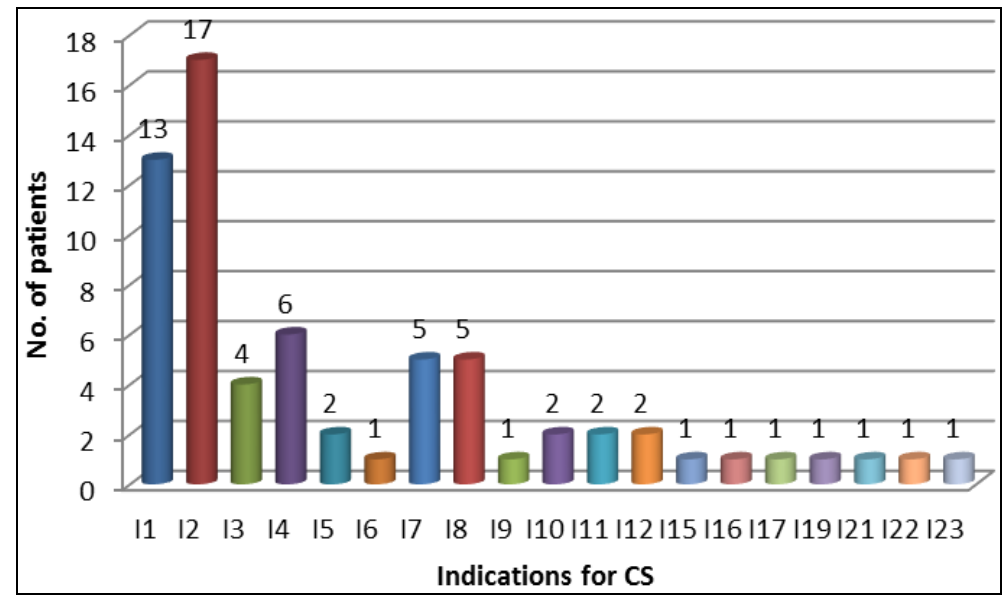

Graph 1: Indication for caesarean section

Graph 1 shows that in 17 cases previous caesarean section in labour, in 13 cases thick meconium stained liquor with foetal distress, in 6 cases failure to progress, in 5 cases cephalopelvic disproportion, in 5 cases premature rupture of membranes and in 4 cases breech presentation in labour.

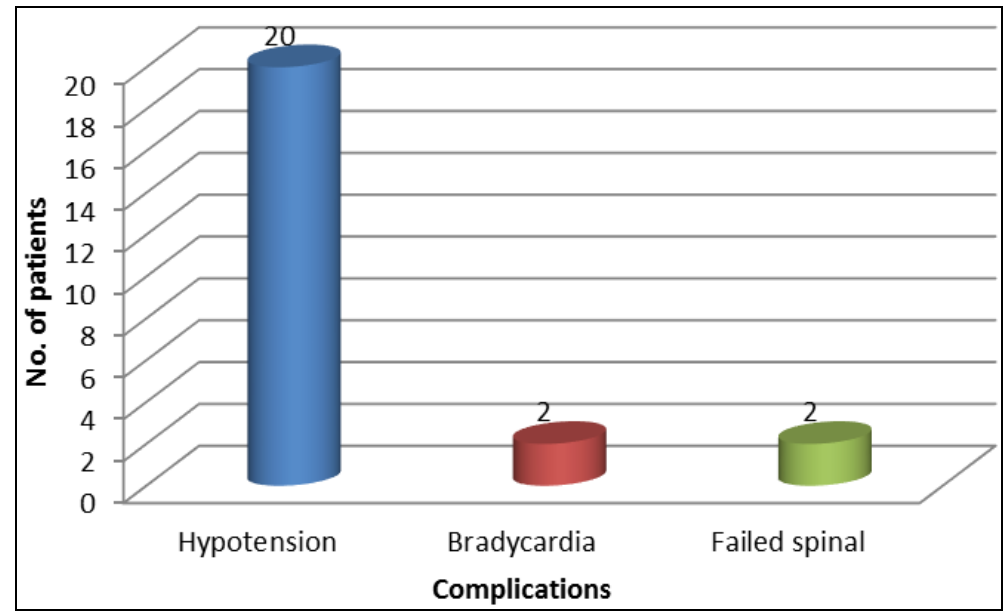

Graph 2: Intraoperative Complications

Graph 2 shows that hypotension was present in 20 cases, bradycardia in 2 cases and failed spinal in 2 cases.

\section{Discussion}

Obstetric anaesthesia is considered to be one of the higher risk areas of anaesthetic practice. Maternal adaptations to pregnancy and the care of the both present unique challenges to the obstetric anaesthesiologist [9]. Maternal mortality has emerged as one of the most challenging health care issue in the last decade, which has become important criteria in assessing country's position on the developmental ladder ${ }^{[10]}$.

Selection of anaesthesia depends on the experience of the anesthetists and obstetrician, the indication and the urgency of the caesarean section, and maternal preference ${ }^{[11]}$. In this study anaesthetic management of 100 obstetric emergencies was studied prospectively. The most common obstetric emergency was lower segment caesarean section followed by surgery for ectopic pregnancy, postpartum hysterectomy for postpartum hemorrhage, other incidental surgeries like bartholin cyst excision, incision and drainage of the abscess and cervical cerclage. The various indications of caesarean section were fetal distress, previous LSCS with failure to progress, breech presentation, twin pregnancy with breech presentation, placenta previa, cephalopelvic disproportion, deep transverse arrest, preeclampsia, transverse lie, placental abruption, eclampsia with HELLP syndrome and uterine inversion ${ }^{[12]}$

The most common indication of caesarean section we encountered is previous caesarean section in labour. $90 \%$ of caesarean sections were performed under subarachnoid block. $8 \%$ of cases were performed under general anaesthesia with rapid sequence induction. In two cases subarachnoid block was converted to general anaesthesia due to failed subarachnoid block.

In a case of multigravida with eclampsia with HELLP syndrome general anaesthesia was given for caesarean section. Patient was shifted to ICU with endotracheal tube in situ since the patient had poor respiratory attempts. However the patient died on $6^{\text {th }}$ postoperative day due to acute respiratory distress syndrome. In another case of primigravida with eclampsia subarachnoid block was given for caesarean section. The patient had uneventful intraoperative and postoperative course.

In another case of multigravida with acute febrile illness, thrombocytopenia, acute lung injury and previous LSCS subarachnoid block was given for caesarean section. The patient's platelet count was $68000 / \mathrm{Cu} \mathrm{mm}$ and she had bilateral crepitations. Her intraoperative and postoperative period was uneventful. 
Subarachnoid block was given for a multigravida with gluteal abscess for incision and drainage. Her intraoperative and postoperative period was uneventful. In another case of primigravida with abruptio placenta was given general anaesthesia for caesarean section since the patient had hypotension. Rapid sequence induction was done with injection ketamine and suxamethonium. In another case of primigravida with multiple haemangioma of spine with cord compression and paraplegia for caesarean section was anesthetized by general endotracheal anaesthesia since the MRI spine showed multiple haemangioma of thoracic and lumbar vertebrae. On the $7^{\text {th }}$ postoperative day patient underwent claviculo manubrectomy with D2 corpectomy, iliac grafting and ACP fixation.

In another case of primigravida with large cystic lesion in the abdomen general anaesthesia was administered for caesarean section. Intraoperatively the patient had hypotension which was treated by intravenous fluids and inj. mephentermine. Postoperative period was uneventful. The mass was hydronephrotic right kidney.

For a case of primigravida with morbid obesity for caesarean section subarachnoid block was given. The patient BMI was $40.1 .6 \mathrm{ml}$ of $0.5 \%$ bupivacaine heavy was administered intrathecally. Even though the bony landmarks were not palpable the subarachnoid space was identified in first attempt. Intraoperative hypotension was treated by intravenous fluids and inj. mephentermine. This is in accordance with et al. ${ }^{[13]}$

In another case of multigravida with twin pregnancy the subarachnoid block was converted to general anaesthesia since the surgery got prolonged. In cases of ruptured ectopic pregnancy patients were administered subarachnoid block if patient was haemodynamically stable. In patients with hemorrhagic shock general anaesthesia was administered.

In two cases of postpartum hemorrhage for hysterectomy general anaesthesia was administered since these patients were in hemorrhagic shock. Intraoperative hypotension was managed by intravenous crystalloids, colloids, blood transfusion and inj dopamine infusion. Postoperatively patients were shifted to ICU with endotracheal tube in situ. In $46 \%$ of caesarean sections performed under subarachnoid block the level attained was T4, T6 in $34 \%$ and T10 in $1 \%$ of the cases. The most common complication of subarachnoid block for caesarean section in our study is hypotension followed by bradycardia and failed spinal. In $4 \%$ of cases postoperative ICU admission was required. There were no maternal deaths on table.

The principal advantages of subarachnoid block for caesarean section are simplicity, speed, reliability, social bondage and minimal fetal drug exposure. The parturient remains awake and the hazards of aspiration are minimized. Disadvantages include high incidence of hypotension, intrapartum nausea and vomiting, the possibility of post dural puncture headache and inability to extend the block. ${ }^{14}$ Advantages of general anaesthesia include rapid induction, less hypotension, cardiovascular stability and better control over airways and ventilation. Major concerns regarding the use of general anaesthesia are difficulty in airway management, acid aspiration, awareness and drug toxicity. ${ }^{15}$

\section{Conclusion}

Authors found that the most common obstetric emergency is lower segment caesarean section followed by surgery for ruptured ectopic pregnancy, postpartum hysterectomy for postpartum hemorrhage, other incidental surgeries like bartholin cyst excision, incision and drainage of the abscess and cervical cerclage. The changeover from general anaesthesia to regional anaesthesia has improved the safety profile in obstetric anaesthesia. Our study confirms single shot subarachnoid block is the most common method of anaesthesia for emergency caesarean sections.

\section{References}

1. Richard I, Mazze, Bengt Kallen. Reproductive outcome after anesthesia and operation during pregnancy: A Registry study of 5405 cases. Am J Obstet Gynacol, 1989, 1178-1185.

2. Shnider M, Grace Margaret Webster. Maternal and fetal hazards of surgery during pregnancy. Am J Obstet Gynacol, 1965, 891-900.

3. Sunanda Gupta. Controversies in obstetric anaesthesia. Indian J Anaesth. 2005; 49(3):180-189.

4. O Regan M. Delivery times for caesarean section at Queen Elizabeth Central Hospital, Balantyre, Malawi: is a $30 \mathrm{~min}$ informed to start of operative delivery time achievable? Anaesthesia. 2003; 58(8):756-759.

5. American Academy of Pediatrics. American College of Obstetricians and Gynecologist. Guidelines for perinatal care. ACOG. Fifth Edition, Washington, DC: AAP, 2002, 147.

6. Russell IF. Technique of anaesthesia for caesarean sections. Raising the standard: a compendium of audit recipes, 2006, 166-7.

7. Seon Brian Yeoh, Sng Ban Leong, Alex Tiong Heng. Anaesthesia for lower-segment caesarean section: Changing perspectives; Indian J Anaesth. 2010; 54(5):409-414.

8. Practice guidelines for obstetric anesthesia. An updated report by the American Society of Anaesthesiologists Task Force on obstetric anesthesia. Anaesthesiology. 2007; 106:843-63.

9. Royal College of Obstetrician and Gynaecologists Clinical Effectiveness Support Unit. The National Sentinal Audit Report. London RCOG, 2001.

10. Kinsella SM, Girgirah K, Scrutton MJ. Rapid sequence spinal anaesthesia for category-1 urgency caesarean section: a case series. Anaesthesia. 2010; 65:644-69.

11. Anaesthesia Banks A, Levy D. General for operative obstetrics. Anaesthesia Intensive Care Med. 2007; 8:317-9.

12. Robert A Dyer, Anthony R Reed. Obstetric Anaesthesia in low resource setting. Best Practice and Research Clinical obstetrics and Gynaecology, 2010, 401-412.

13. Charles S Algert, Jennifer R Brown, Warwick B Giles. Regional block versus general anaesthesia for caesarean section and neonatal outcomes: a population based study. BMC Medicine. 2009; 7:7-20.

14. Bucklin BA, Hawkins JL, Anderson JR, Ullrich FA. Obstetric Anesthesia Workforce Survey. Twenty year update. Anesthesiology. 2005; 103:645-53.

15. Alen McGlenman, Adnan Mustafa. General anaesthesia for caesarean section. Continuing medical education in Anaesthesia, Critical care and Pain. 2009; 9:148-151. 